\title{
Potencial de imagens do Sentinel-2 na estimativa da biomassa de Tectona grandis L.f.
}

\section{a Amazônia Ocidental}

\author{
Sentinel-2 imaging potential in estimating the biomass of Tectona grandis L.f. in the Western
}

Amazon

Potencial de imagen de Sentinel-2 para estimar la biomasa de Tectona grandis L.f. en el Amazonas

Occidental

Recebido: 16/08/2021 | Revisado: 21/08/2021 | Aceito: 23/08/2021 | Publicado: 25/08/2021

Ederson José da Silva

ORCID: https://orcid.org/0000-0002-7925-3072 Universidade Federal de Rondônia, Brasil E-mail: edersonsilva.egf@hotmail.com

Diogo Martins Rosa

ORCID: https://orcid.org/0000-0003-3427-8353 Secretaria de Estado do Desenvolvimento Ambiental, Brasil E-mail: mrosa.diogo@gmail.com

Jhony Vendruscolo

ORCID: https://orcid.org/0000-0003-3043-0581

Universidade Federal do Amazonas, Brasil

E-mail: jhonyvendruscolo@gmail.com

Wanderson Cleiton Schmidt Cavalheiro

ORCID: https://orcid.org/0000-0003-1356-8511

Cavalheiro Engenharia Rural e Empresarial Ltda, Brasil

E-mail: engflo.ro@gmail.com

\begin{abstract}
Resumo
Objetivou-se avaliar o potencial de imagens do satélite Sentinel-2 para estimar a biomassa de Tectona grandis L.f., em Rolim de Moura - RO. A metodologia é composta por 7 passos: 1) Inventário florestal em 10 parcelas; 2) Seleção e abate de 20 árvores para obtenção da biomassa de amostras em laboratório; 3) Estimativa da biomassa por parcela por meio de modelos matemáticos; 4) Estimativa de biomassa por sensoriamento remoto nos períodos seco e chuvoso, a partir das imagens do satélite Sentinel-2 (NDVI, EVI-1, EVI-2 e SAVI); 5) Análises de correlação, ajuste e seleção de equações com dados de biomassa (variável dependente) em função das variáveis derivadas das imagens (variáveis independentes); Avaliação da diferença das variáveis independentes adquiridas nos períodos seco e chuvoso; e 7) Quantificação e espacialização da biomassa para a área de estudo. O modelo de Schumacher e Hall - Log. foi o melhor para obtenção da biomassa. As variáveis das imagens diferem entre os períodos seco e chuvoso. As correlações entre a biomassa e as variáveis das imagens foram maiores no período chuvoso. As variáveis que melhor estimam a biomassa foram obtidas no período chuvoso, sendo selecionada a equação 1 (Y=35,625331-528,123868*B02) $2,653078 * \mathrm{~B} 03+273,491 * \mathrm{~B} 04+92,572857 * \mathrm{EVI}-1-108,785571 * \mathrm{EVI}-2-22,807912 * \mathrm{NDVI})$. A estimativa da biomassa por meio de imagens do Sentinel-2 são precisas e úteis para o monitoramento da biomassa florestal, contudo, recomenda-se ajustes nos modelos matemáticos e estudos com diferentes sensores.
\end{abstract}

Palavras-chave: Sensoriamento remoto; Povoamentos florestais; Índices de vegetação.

\begin{abstract}
The objective was to evaluate the potential of Sentinel-2 satellite images to estimate the biomass of Tectona grandis L.f., in Rolim de Moura - RO. The methodology consists of 7 steps: 1) Forest inventory in 10 plots; 2) Selection and felling of 20 trees to obtain biomass from laboratory samples; 3 ) Estimation of biomass by plot using mathematical models; 4) Biomass estimation by remote sensing in dry and rainy periods, based on Sentinel-2 satellite images (NDVI, EVI-1, EVI-2 and SAVI); 5) Analysis of correlation, adjustment and selection of equations with biomass data (dependent variable) as a function of variables derived from the images (independent variables); Evaluation of the difference of independent variables acquired in the dry and rainy periods; and 7). Quantification and spatialization of biomass for the study area. The Schumacher and Hall - Log. model was the best for obtaining biomass. Image variables differ between dry and rainy periods. Correlations between biomass and image variables were higher in the rainy season. The variables that best estimate biomass were obtained in the rainy season, with equation 1 being selected $(\mathrm{Y}=35.625331-528.123868 * \mathrm{~B} 02)-2.653078 * \mathrm{~B} 03+273.491 * \mathrm{~B} 04+92.572857 * \mathrm{EVI}-1-\quad 108.785571 * \mathrm{EVI}-2-$ $22.807912 * \mathrm{NDVI})$. Biomass estimates using Sentinel-2 images are accurate and useful for monitoring forest biomass, however, adjustments in mathematical models and studies with different sensors are recommended.
\end{abstract}

Keywords: Remote sensing; Forest settlements; Vegetation indices. 


\begin{abstract}
Resumen
El objetivo de este estudio fue evaluar el potencial de las imágenes satelitales Sentinel-2 para estimar la biomasa de Tectona grandis L.f., en Rolim de Moura - RO. La metodología consta de 7 pasos: 1) Inventario forestal en 10 parcelas; 2) Selección y tala de 20 árboles para obtener biomasa de muestras de laboratorio; 3 ) Estimación de biomasa por parcela utilizando modelos matemáticos; 4) Estimación de biomasa por teledetección en época seca y lluviosa, basada en imágenes satelitales Sentinel-2 (NDVI, EVI-1, EVI-2 y SAVI); 5) Análisis de correlación, ajuste y selección de ecuaciones con datos de biomasa (variable dependiente) en función de variables derivadas de las imágenes (variables independientes); Evaluación de la diferencia de variables independientes adquiridas en los períodos seco y lluvioso; y 7) Cuantificación y espacialización de biomasa para el área de estudio. El modelo Schumacher y Hall-Log. Fue el mejor para la obtención de biomasa. Las variables de imagen difieren entre períodos secos y lluviosos. Las correlaciones entre la biomasa y las variables de imagen fueron mayores en la temporada de lluvias. Las variables que mejor estiman la biomasa se obtuvieron en la época de lluvias, seleccionándose la ecuación 1 ( $\mathrm{Y}=35.625331-528.123868 *$ B02) $2.653078 * \mathrm{~B} 03+273.491 * \mathrm{~B} 04+92.572857 *$ EVI-1- 108.785571 * EVI-2-22.807912* NDVI). Las estimaciones de biomasa que utilizan imágenes de Sentinel-2 son precisas y útiles para monitorear la biomasa forestal, sin embargo, se recomiendan ajustes a los modelos matemáticos y estudios con diferentes sensores.
\end{abstract}

Palabras clave: Detección remota; Rodales forestales; Índices de vegetación.

\title{
1. Introdução
}

As florestas plantadas têm grande importância nos setores econômico e ambiental, por suprir parte das demandas por produtos de origem florestal, reduzindo a pressão sobre as florestas nativas, e auxiliar na mitigação dos problemas ocasionados pelo aumento do efeito estufa. No Brasil, estima-se que existam aproximadamente 7,84 milhões de hectares de reflorestamento, responsável por $91 \%$ da madeira produzida para fins industriais a nível nacional, e 6,2\% do Produto Interno Bruto (PIB) industrial do País (Ibá, 2017).

A Tectona grandis L.f., popularmente conhecida como Teca, é nativa das florestas tropicais do Sudeste Asiático. Esta espécie é caducifófia, tem rápido crescimento, altura de 25 a $30 \mathrm{~m}$, tronco retilíneo, pouco sujeita a pragas e doenças (Macedo et al., 2005), resistente e de excelente qualidade (Lima et al., 2009). Essas características tornam sua madeira valorizada, sendo uma das espécies florestais mais cultivadas no mundo, com área plantada de 6,9 milhões de hectares no ano de 2015 (Midgley et al., 2015).

Nos últimos anos, elevou-se a preocupação em relação às mudanças climáticas do planeta, ocasionadas pelo aumento das emissões de gás carbônico (CO2) (Cramer et al., 2001). Como alternativa para a redução desses efeitos, está a remoção e fixação do $\mathrm{CO} 2$ da atmosfera para a biosfera terrestre, por meio do processo de fotossíntese realizado pelas plantas (Davidson et al., 2005). Portanto, as florestas e os plantios florestais têm função especial no ciclo do CO2, sendo consideradas importantes sumidouros de carbono, devida à sua capacidade em fixar carbono na forma de biomassa (Davidson et al., 2005; Sanquetta et al., 2014).

Em função do elevado potencial das plantas para fixação de $\mathrm{CO} 2$, aumentou-se a demanda por estudos e técnicas relacionadas à quantificação de biomassa florestal, que pode ser realizada por métodos diretos e indiretos. O método direto consiste em cortar as árvores e separar seus componentes, que posteriormente serão pesados. No método indireto empregam-se equações alométricas ou técnicas de sensoriamento remoto, para a realização das estimativas. Assim, verifica-se a importância do desenvolvimento de novos métodos para determinar e estimar a biomassa, com redução de custos e com ganho de confiabilidade de sua estimativa (Watzlawick et al., 2009; Nicoletti et al., 2015).

Os satélites, através da captura e processamento de imagens digitais, possibilitam a obtenção de informação de áreas por sensoriamento remoto, ou seja, sem o contato físico com os objetos a serem estudados. Portanto, através das técnicas de sensoriamento, é possível avaliar os métodos indiretos para estimar os parâmetros da vegetação (altura, volume, biomassa, carbono, etc.). Esses dados podem ser validados com informações obtidas em campo, para se aumentar a confiabilidade das estimativas (Watzlawick et al., 2009; Alba et al., 2017).

Em face ao exposto, objetivou-se avaliar a potencialidade da utilização de imagens do satélite Sentinel-2 para estimar a 
biomassa de plantio de Teca (Tectona grandis L.f.).

\section{Metodologia}

\subsection{Localização e caracterização da área de estudo}

O trabalho foi realizado em plantio de Tectona grandis L.f, localizado no município de Rolim de Moura/RO (Figura 1). A região tem clima Tropical do tipo Monção (Alvares et al., 2013), temperatura do ar entre 24 e $27{ }^{\circ} \mathrm{C}$, precipitação pluvial entre 1.650 e $1.850 \mathrm{~mm} \mathrm{ano}^{-1}$, período seco definido entre os meses de maio a setembro (SEDAM, 2010), relevo plano a suave ondulado (EMBRAPA, 1979), altitudes de 240 a 261 m, (ASF, 2017) e Latossolo Vermelho-Amarelo distrófico (Vendruscolo, 2012).

Figura 1. Localização da área de plantio de Tectona grandis e das parcelas no município de Rolim de Moura, Rondônia.
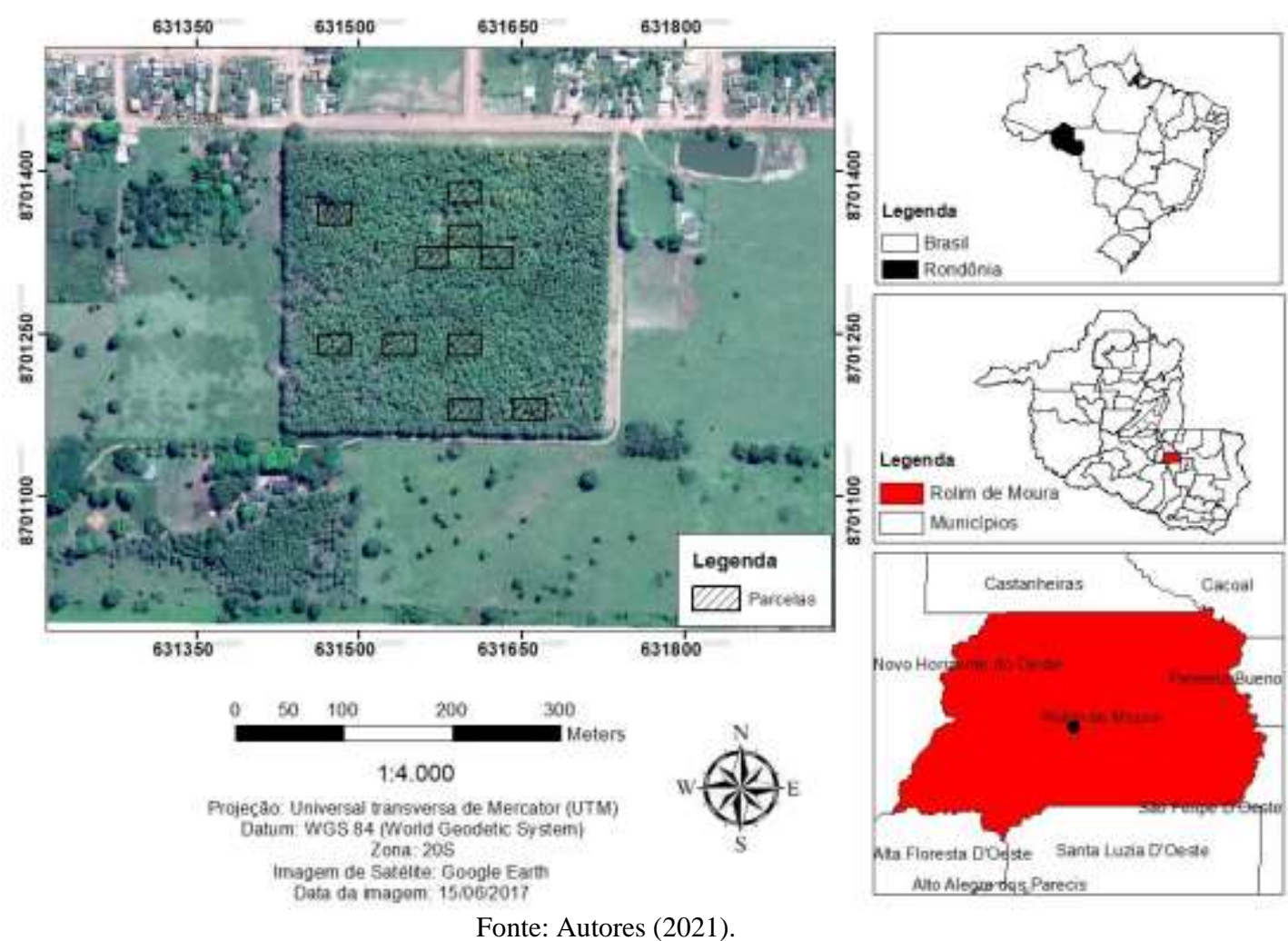

Fonte: Autores (2021).

\subsection{Inventário florestal e determinação da biomassa acima do solo}

O plantio de Teca foi realizado no ano de 2007, em uma área de 8,4 ha com espaçamento de 2,5 x 2,5 m. Foram realizadas desramas periodicamente e o desbastamento aleatório de 58\% dos indivíduos. Em novembro de 2017, após 10 anos de implantação, realizou-se um inventário florestal temporário em 10 unidades amostrais, com área de $600 \mathrm{~m}^{2}(20 \times 30 \mathrm{~m})$, distribuídas aleatoriamente na área do plantio (Figura 1). Em cada unidade amostral todos os indivíduos foram mensurados, para cada indivíduo foi obtido o diâmetro altura do peito (DAP) com uma suta diamétrica e a altura total (HT) por meio do hipsômetro Haglof. Posteriormente, as árvores foram agrupadas em classes de DAP considerando uma amplitude de 2,2 cm, totalizando cinco classes de DAP (Tabela 1). 
Tabela 1. Classes diamétricas e intervalos de classe para o plantio comercial de T. grandis em Rolim de Moura, Rondônia.

\begin{tabular}{|c|c|c|c|c|}
\hline Classes & DAP (cm) & Frequência (fi) & Média de DAP(cm) & Média de altura (m) \\
\hline $\mathrm{I}$ & $12,89-15,09$ & 36 & 14,47 & 15,14 \\
\hline II & $15,10-17,29$ & 143 & 16,32 & 16,24 \\
\hline III & $17,30-19,49$ & 167 & 18,33 & 17,15 \\
\hline IV & $19,50-21,69$ & 52 & 20,45 & 17,81 \\
\hline V & $21,70-23,89$ & 12 & 22,89 & 19,22 \\
\hline
\end{tabular}

Fonte: Autores (2021).

Para cada classe diamétrica foram escolhidas quatro árvores, com DAP mais próximo do centro de classe. Estas 20 árvores foram abatidas e tiveram o fuste seccionado em toretes de um metro $(1 \mathrm{~m})$ de comprimento, e realizou-se a cubagem rigorosa pelo método de Smalian (Finger, 2006). Além disso, os demais compartimentos (folhas, galhos) foram separados e pesados em campo utilizando-se uma balança mecânica, obtendo-se o peso verde de biomassa para cada compartimento.

Para determinação de massa seca em laboratório, foi retirada uma amostra para cada compartimento (galhos e folhas), com exceção para o fuste (madeira com casca), onde foram retirados discos a cada metro do tronco, contendo aproximadamente $3 \mathrm{~cm}$ de espessura.

No laboratório foram retiradas duas cunhas opostas de cada disco, onde foram levadas para serem secas em estufa a 105 ${ }^{\circ} \mathrm{C}$. Após a secagem, as cunhas foram pesadas e também submetidas ao método de deslocamento de água para determinação do seu volume. Já com os parâmetros de massa seca e volumes determinados, obteve-se valores de massa específica básica. Para determinar o valor de biomassa seca relacionou-se a massa específica básica ponderada com o volume do componente, que no caso do estudo, a casca e o fuste das árvores. A biomassa seca acima do solo de cada árvore foi obtida pelo somatório dos pesos de cada compartimento.

\subsection{Estimativa de biomassa a partir das imagens do satélite Sentinel-2}

\subsubsection{Aquisição das imagens}

Foram utilizadas imagens do satélite Sentinel-2A, sensor MSI (MultiSpectral Instrument), bandas B02, B03, B04 e B08 (USGS, 2018). A resolução espacial do Sentinel-2A pode ser visualizada na Tabela 2 (ESA, 2017).

Tabela 2. Resolução espacial, espectral e radiométrica das bandas do sensor MSI (MultiSpectral Instrument) do satélite Sentinel2.

\begin{tabular}{|c|c|c|c|}
\hline Resolução & $N^{o}$ da Banda & Nome da Banda & $\begin{array}{c}\text { Comprimento de onda } \\
\text { central }(\text { micrômetro }-\mu \mathrm{m})\end{array}$ \\
\hline \multirow{4}{*}{$10 \mathrm{~m}$} & B02 & Blue & 0,49 \\
\hline & B03 & Green & 0,56 \\
\hline & B04 & Red & 0,66 \\
\hline & B08 & NIR & 0,84 \\
\hline \multirow{6}{*}{$20 \mathrm{~m}$} & B05 & Red Edge 1 & 0,70 \\
\hline & B06 & Red Edge 1 & 0,74 \\
\hline & B07 & Red Edge 1 & 0,78 \\
\hline & B08A & Red Edge 1 & 0,86 \\
\hline & B11 & SWIR 1 & 1,61 \\
\hline & $\mathrm{B} 12$ & SWIR 2 & 2,19 \\
\hline \multirow{3}{*}{$60 \mathrm{~m}$} & B01 & Aerossol & 0,44 \\
\hline & B09 & Water Vapor & 0,94 \\
\hline & $\mathrm{B} 10$ & Cirrus & 1,37 \\
\hline
\end{tabular}

Fonte: ESA (2017). 
Para o estudo utilizou-se duas imagens de satélite, a primeira no período seco, adquirida em 25/09/2017 e a segunda no período chuvoso referente ao dia 04/03/2018. A escolha dessas duas imagens em épocas diferentes, mas com passagens (datas) relativamente próximas à data de retirada das árvores, é explicada pelo fato de que se pretendia minimizar o tempo entre a coleta de dados em campo e a disponibilidade de dados orbitais de boa qualidade.

\subsubsection{Processamento das imagens orbitais}

O processamento das imagens foi realizado através do programa software SIG ArcGIS versão 10.2.2 (versão estudante), o sistema de projeção utilizado para todas as imagens foi o Universal Transversa de Mercator (UTM), Zona 20S e Datum WGS 1984. Os dados utilizados contam com imagem geometricamente corrigida (ortorretificada) e valores de reflectância no topo da atmosfera (TOA) (ESA, 2017). A cena apresentou 0,5\% de cobertura de nuvens na cena, não afetando a área de estudo.

Para geração dos índices, as imagens correspondentes a cada banda do sensor foram recortadas com uma máscara shapefile da área correspondente ao limite do município obtidos do Instituto Brasileiro de Geografia e Estatística (IBGE, 2012), e em seguida foram gerados os índices de vegetação utilizando a ferramenta Raster Calculator.

\subsubsection{Cálculo dos índices de vegetação}

Os índices de vegetação utilizados para estimar a biomassa seca foram: (i) Índice de Vegetação por Diferença Normalizada (NDVI); (ii) Índice de Vegetação Ajustado para o Solo (SAVI); (iii) Índice de Vegetação Melhorado (EVI-1); (iv) Índice de Vegetação adaptado (EVI-2).

O Índice de Vegetação por Diferença Normalizada (NDVI) varia de -1 a 1, onde valores altos correspondem à alta densidade de vegetação, enquanto valores baixos correspondem a vegetação menos densa (Boratto \& Gomide, 2013), e foi calculado com a Equação 1.

$N D V I=\left(\frac{N I R-R E D}{N I R+R E D}\right)$ (Equação 1)

Em que: NDVI = Índice de vegetação por diferença normalizada; NIR = Reflectância na banda 08 (infravermelho próximo); RED = Reflectância na banda 04 (vermelho);

O Índice de Vegetação Ajustado para o Solo (SAVI), criado para reduzir o efeito de solo (Rouse et al., 1973; Huete, 1988), foi calculado com a Equação 2.

$S A V I=\left(\frac{N I R-R E D}{N I R+R E D+L}\right) x(1+L)$ (Equação 2)

Em que: NIR = Reflectância na banda 08 (infravermelho próximo); RED = Reflectância na banda 04 (vermelho); L = fator de correção para o solo.

O valor do fator L, introduzido a fim de diminuir a influência do brilho do solo e produzir isolinhas de vegetação mais independentes do solo, pode variar de 0 a 1, depende do grau de cobertura do solo, sendo 0,25 para vegetações densas, 0,50 para um grande intervalo de condições de vegetação e 1 para vegetações abertas (Huete, 1988). Nesse estudo utilizou-se o valor da constante $\mathrm{L}=0,50$, por ser considerada ideal para os diversos ambientes (Huete, 1988). 
O Índice de Vegetação Melhorado (EVI) minimiza os efeitos de solos e da atmosfera, sendo mais sensível às variações que ocorrem na estrutura do dossel (Huete et al., 1997). Esse índice emprega as bandas espectrais do infravermelho próximo, do vermelho e do azul, para indicar o vigor vegetativo, e foi mensurado com as Equações 3 e 4.

$E V I_{1}=2,5 \times\left(\frac{N I R-R E D}{N I R+(6 \times R E D)-(7,5 \times B L U)+1}\right)$

(Equação 3)

Em que: NIR = Reflectância na banda 08 (infravermelho próximo); RED = Reflectância na banda 04 (vermelho); BLUE = Reflectância na banda 02 (azul).

$E V I_{2}=2,5 x\left(\frac{N I R-R E D}{N I R+(2,4 \times R E D)+1}\right)$

(Equação 4)

Em que: NIR = Reflectância na banda 08 (infravermelho próximo); RED = Reflectância na banda 04 (vermelho).

Em trabalho realizado por Jiang et al. (2008) foi desenvolvido um novo índice de vegetação baseado no $\mathrm{EVI}_{1}$, denominado $\mathrm{EVI}_{2}$, entretanto sem a banda do azul. $\mathrm{O} \mathrm{EVI}_{2}$ visa decompor a equação $\mathrm{EVI}_{1}$ para eliminar a banda azul, assumindo que a reflectância na banda azul pode ser expressa como uma função na banda vermelha. $\mathrm{O} \mathrm{EVI}_{2}$ pode assumir diferentes funções de resposta espectral vermelho ou azul, por ser desenvolvido com base em dados do sensor MODIS (Moderate Resolution Imaging Spectroradiometer), por isso a relação entre $\mathrm{EVI}_{1}$ e $\mathrm{EVI}_{2}$ pode variar ligeiramente de um sensor para outro (Jiang et al., 2008) (Equação 4).

\subsubsection{Obtenção dos valores de reflectância e dos índices}

Para cada unidade amostral foi adquirida a coordenada do centro e dos limites das parcelas com o auxílio do GPS Garmin Map 64SC. Utilizando as coordenadas das unidades amostrais, foram geradas as parcelas em função do tamanho da unidade amostral $(20$ x 30 m). Para cada imagem foram retirados os valores médios de 6 pixels (Figura 2). Este procedimento foi realizado nas bandas B02, B03, B04 e B08, assim como para os índices de vegetação: NDVI, SAVI, EVI 1 e EVI 2 . 
Figura 2. Representação da obtenção dos valores médios dos pixels para o Índice de Vegetação da Diferença Normalizada (NDVI) de uma unidade amostral.

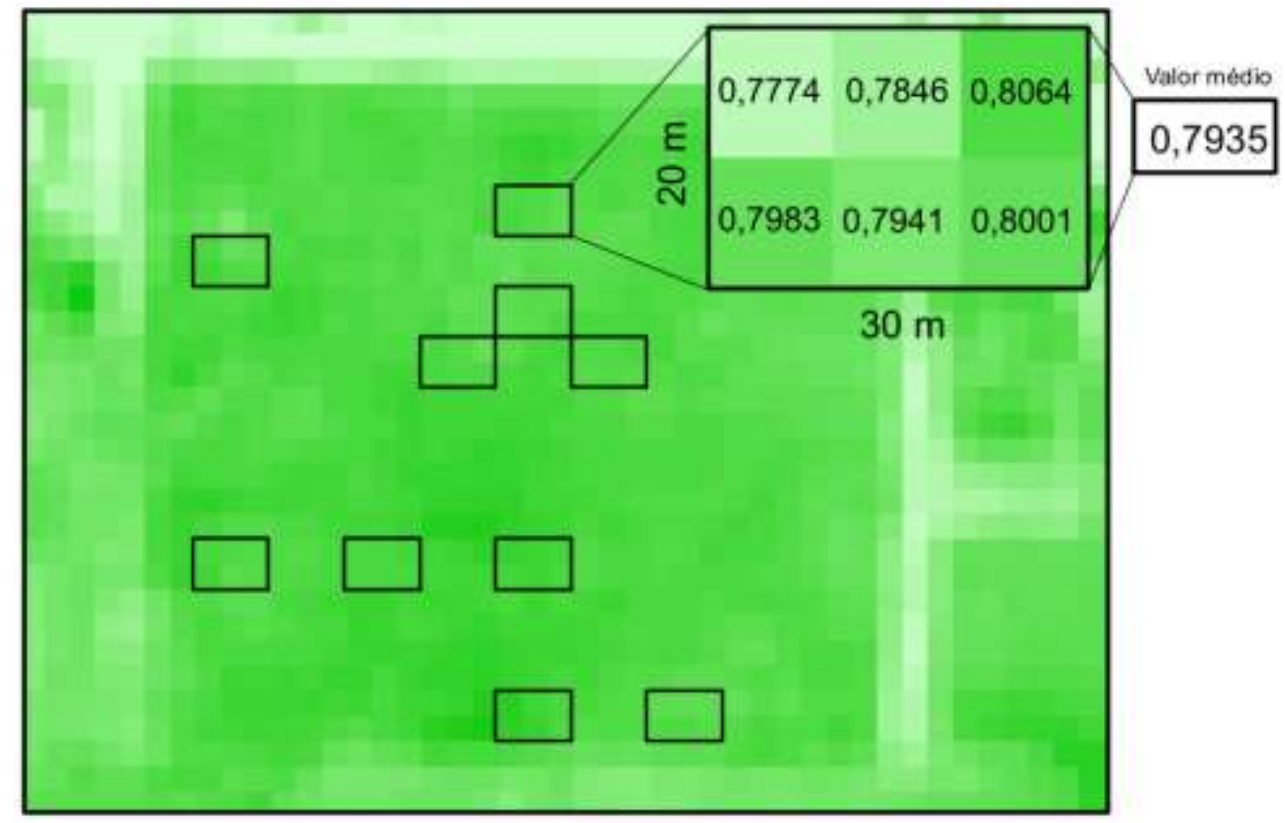

Fonte: Autores (2021).

\subsection{Análises dos dados}

Com os dados de biomassa, diâmetro (DAP) e altura total (HT) das árvores amostradas, foram realizadas a análise descritiva e o teste de normalidade de Shapiro-Wilk ( $\mathrm{p}<0,05)$. Assim, para obtenção da biomassa acima do solo das parcelas do inventário foram escolhidas e testadas quatro modelos que, de acordo com a literatura, proporciona as melhores respostas nas estimativas de volume (Cerqueira et al., 2017), biomassa (Melo et al., 2004; Miranda et al., 2011; Bohrer, Chaubey \& Singhal, 2013) e carbono (Melo et al., 2004; Miranda et al., 2011) em plantios florestais (Tabela 3).

Tabela 3. Modelos para estimativa de biomassa de Tectona grandis em Rolim de Moura, Rondônia.

\begin{tabular}{lll}
\hline $\mathbf{N}$ & Modelos & Denominação \\
\hline 1 & $\ln \mathrm{Y}=\mathrm{b}_{0}+\mathrm{b}_{1} \ln \mathrm{DAP}+\mathrm{b}_{2} \ln \mathrm{HT}+\varepsilon$ & Schumacher e Hall $^{1}$ \\
2 & $\mathrm{Y}=\mathrm{b}_{0}+\mathrm{b}_{1}\left(\mathrm{DAP} \mathrm{HT}^{2}+\varepsilon\right.$ & Spurr \\
3 & $\mathrm{Y}=\mathrm{b}_{0}+\mathrm{b}_{1} \mathrm{DAP}+\varepsilon$ & Berkhout (Linear Simples) \\
4 & $\mathrm{Y}=\mathrm{b}_{0}+\mathrm{b}_{1} \mathrm{DAP}+\mathrm{b}_{2} \mathrm{DAP}^{2}+\mathrm{b}_{3} \mathrm{DAP}^{3}+\mathrm{b}_{4} \mathrm{DAP}^{4}+\varepsilon$ & $*$ \\
\hline
\end{tabular}

Fonte: Autores (2021).

Após gerar as equações de biomassa, foi escolhida a melhor equação, conforme as análises descritas no penúltimo parágrafo deste tópico, em seguida, estimou-se a biomassa acima do solo por parcela, aplicando a equação escolhida nos indivíduos presentes nas 10 parcelas do inventário florestal.

A biomassa obtida a campo foi considerada variável dependente, e os valores de reflectância provenientes das imagens de sensoriamento remoto foram considerados variáveis independentes. Para avaliar os dados de biomassa seca acima do solo e as informações das imagens, inicialmente, foi realizada uma análise descritiva das variáveis independentes e um teste t pareado $(\mathrm{p}<0,05)$, para detectar diferenças dos valores do período seco e chuvoso. Após isso, as variáveis dependentes e independentes 
foram submetidas à análise de correlação de Pearson, com o critério de classificação conforme Mukaka (2012), sendo as variáveis independentes referentes ao período seco e chuvoso.

Para a análise envolvendo os dados obtidos das imagens para verificar quais variáveis independentes que melhor estimam os valores de biomassa acima do solo, utilizou-se o procedimento de análise de regressão múltipla, empregando-se, para tanto, o procedimento Stepwise com as técnicas forward e backward sugeridos por Neter et al. (1996).

Nas análises de regressão realizadas neste trabalho, visando a julgar qual a melhor equação que estima adequadamente a biomassa acima do solo, foram realizadas análises do coeficiente de determinação ajustado $\left(R_{\text {aj), erro-padrão da estimativa }}^{2}\right.$ ( $\left.\mathrm{S}_{\mathrm{yx}} \%\right)$, Critério de Informação de Akaike (AIC), Critério de Informação Bayesiano (BIC), distribuição dos resíduos e teste $\mathrm{F}$ dos coeficientes. Para os modelos logarítmicos, os valores estimados foram obtidos por antilogaritmização natural seguida de aplicação do Fator de Correção de Meyer (FCM), todas as fórmulas estão descritas em Sanquetta et al. (2015). Todas as análises estatísticas foram feitas no software estatístico R, versão 3.5.0 (R Core Team, 2018).

A equação ajustada e selecionada com seus respectivos coeficientes foi aplicada às variáveis selecionadas (imagens e índices), obtendo-se como resultados a tabela e o mapa com os valores estimados de biomassa seca acima do solo.

\section{Resultados e Discussão}

\subsection{Ajuste de modelos alométricos e seleção de equações para estimativa de biomassa acima do solo}

Os indivíduos abatidos têm diâmetro médio de $18,41 \mathrm{~cm}$, variando de 13,65 até 23,11 cm, e um valor médio de 132,68 kg para biomassa seca, com desvios-padrão de 53,68 kg (Tabela 4).

Tabela 4. Estatística descritiva e teste de normalidade para os parâmetros Diâmetro a altura do peito, altura total e biomassa de indivíduos de Tectona grandis, município de Rolim de Moura, Rondônia.

\begin{tabular}{|c|c|c|c|c|c|c|c|}
\hline \multirow{2}{*}{ Variáveis } & \multirow{2}{*}{ Média } & \multirow{2}{*}{ Mínimo } & \multirow{2}{*}{ Máximo } & \multirow{2}{*}{$\begin{array}{l}\text { Coeficiente de } \\
\text { Variação }(\%)\end{array}$} & \multirow{2}{*}{$\mathbf{N}$} & \multicolumn{2}{|c|}{ Teste de Normalidade } \\
\hline & & & & & & p-valor & normal \\
\hline $\begin{array}{l}\text { Diâmetro a altura do peito } \\
\text { (cm) }\end{array}$ & 18,41 & 13,65 & 23,11 & 17,16 & 20 & $>0,05$ & Sim \\
\hline Altura total (m) & 16,95 & 12,30 & 22,30 & 12,45 & 20 & $>0,05$ & Sim \\
\hline Biomassa seca $(\mathrm{kg})$ & 132,68 & 62,05 & 222,89 & 40,46 & 20 & $>0,05$ & Sim \\
\hline
\end{tabular}

Fonte: Autores (2021).

Entre os quatro modelos testados, destacam-se os de Schumacher e Hall - log. (1993) e de Spurr (1952), estes tiveram os maiores valores de $\mathrm{R}^{2}$ aj e os menores de $\mathrm{S}_{\mathrm{xy}} \%$, porém o modelo de Schumacher \& Hall (1993) foi o que teve o maior valor de $\mathrm{R}^{2} \mathrm{aj}=0,94$, menor valor de $\mathrm{S}_{\mathrm{xy}} \%=9,46$, os menores valores de $\mathrm{AIC}=-24,37$ e BIC = -20,39, e a melhor distribuição de resíduos (Tabela 5 e Figura 3). Este modelo alométrico é usualmente utilizado nas estimativas de volume, e podem ser utilizados para estimar biomassa, com resultados satisfatórios (Husch et al., 2003). 
Tabela 5. Indicadores estatísticos dos modelos para estimativa de biomassa seca acima do solo em plantio comercial de Tectona grandis em Rolim de Moura, Rondônia.

\begin{tabular}{cccccc}
\hline Modelo & FCM & $\mathbf{R}^{\mathbf{2}_{\text {aj }}}$ & $\mathbf{S}_{\mathbf{y x}}(\boldsymbol{\%})$ & $\mathbf{A I C}$ & $\mathbf{B I C}$ \\
\hline 1 & 1,0068 & 0,9453 & 9,46 & $-24,37$ & $-20,39$ \\
2 & & 0,9394 & 9,96 & 163,92 & 166,90 \\
3 & & 0,9363 & 10,21 & 164,89 & 167,88 \\
4 & & 0,9316 & 10,58 & 169,95 & 175,93 \\
\hline
\end{tabular}

FCM: Fator de Correção de Meyer; $\mathrm{R}_{\text {aj: }}^{2}$ coeficiente de determinação ajustado; $\mathrm{S}_{\mathrm{yx}}(\%)$ : erro padrão da estimativa; AIC: Critério de Informação de Akaike e BIC: Critério de Informação Bayesiano. Fonte: Autores (2021).

Figura 3. Distribuição dos resíduos das equações ajustadas dos modelos 1 (Schumacher e Hall - linearizado), 2 (Spurr), 3 (Berkhout) e 4 para estimativa de biomassa seca acima do solo de um plantio Tectona grandis em Rolim de Moura, Rondônia.
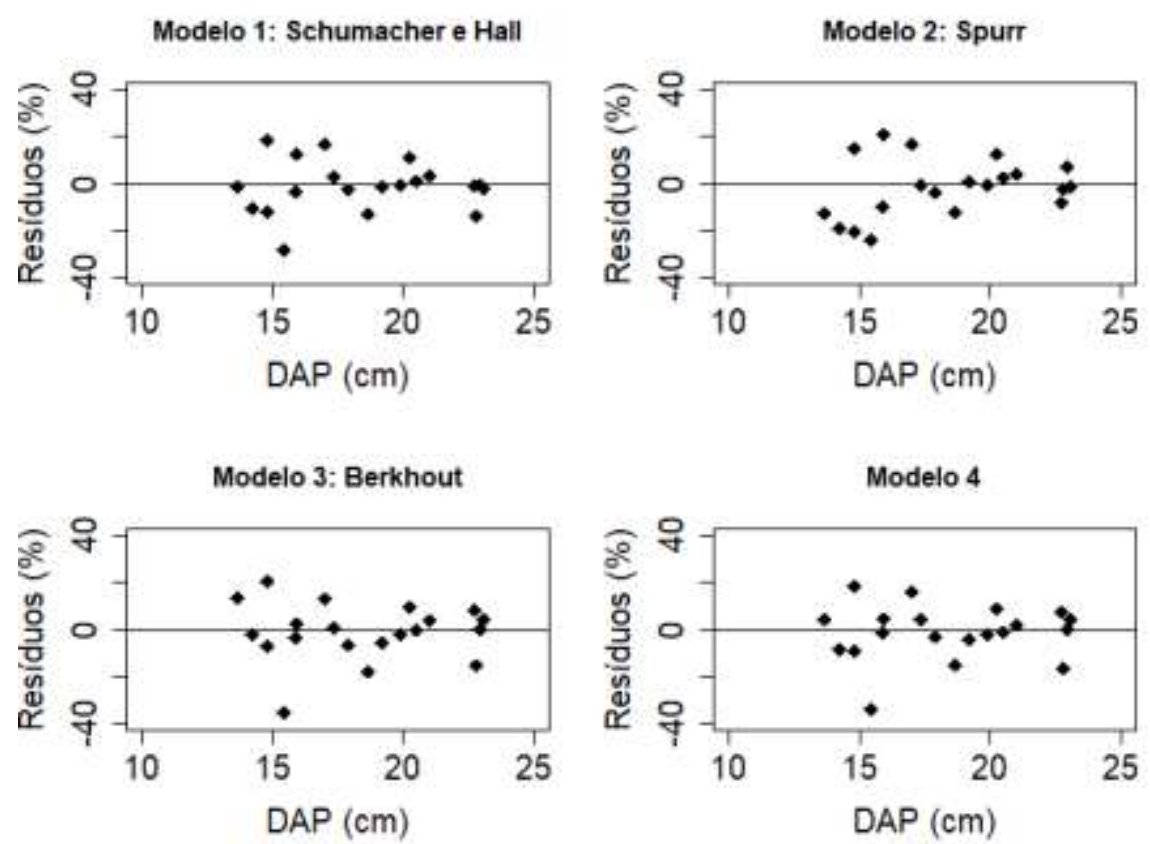

Fonte: Autores (2021).

Para os coeficientes, verifica-se que somente o modelo de Berkhout teve todos seus coeficientes significativos pelo teste F (Tabela 6), porém o modelo de Schumacher \& Hall - $\log$ somente o coeficiente $b_{2}$, referente à altura, não foi significativo. Isso pode ser devido à falta de relação de altura e diâmetro para a T. grandis, neste estudo obteve-se correlações (r) entre o DAP x HT de 0,57 e HT x Biomassa de 0,64, porém são necessários mais estudos para avaliar essa relação.

Tabela 6. Coeficientes dos modelos de biomassa seca acima do solo de um plantio Tectona grandis em Rolim de Moura, Rondônia.

\begin{tabular}{llllll}
\hline Modelo & $\mathbf{b}_{\mathbf{0}}$ & $\mathbf{b}_{\mathbf{1}}$ & $\mathbf{b}_{2}$ & $\mathbf{b}_{\mathbf{3}}$ & $\mathbf{b}_{\mathbf{4}}$ \\
\hline 1 & $-2,6743205^{* * *}$ & $2,2341052^{* * *}$ & $0,3548152^{\mathrm{ns}}$ & & \\
2 & $12,33569428^{\mathrm{ns}}$ & $0,01982416^{* * *}$ & & & \\
3 & $-170,61773^{* * *}$ & $16,47457^{* * *}$ & & & $-0,02208^{\mathrm{ns}}$ \\
4 & $-1845,6^{\mathrm{ns}}$ & $437,5974^{\mathrm{ns}}$ & $-38,52671^{\mathrm{ns}}$ & $1,52452^{\mathrm{ns}}$ & \\
\hline
\end{tabular}

$b_{n}$ : coeficientes da regressão; ${ }^{\text {ns }}$ coeficiente não significativo $(\mathrm{p}>0,05) ;{ }^{* * *}$ coeficiente significativo $(\mathrm{p}<0,01)$. Fonte: Autores $(2021)$. 
Dessa forma, o modelo 4 (Schumacher \& Hall - log.) foi o selecionado para estimar os valores de biomassa seca acima do solo por parcela (Tabela 7). Na literatura, observa-se que este modelo tem melhores estimativas e com menores tendências para as variáveis volume, biomassa e carbono (Scolforo et al., 2008; Miranda, Melo \& Sanquetta, 2011; Sanquetta et al., 2014).

Tabela 7. Biomassa acima do solo das 10 parcelas do inventário florestal de um plantio de Tectona grandis em Rolim de Moura, Rondônia.

\begin{tabular}{cccccccc}
\hline \multirow{2}{*}{$\begin{array}{c}\mathbf{N}^{\mathbf{0}} \mathbf{d a} \\
\text { Parcela }\end{array}$} & \multicolumn{3}{c}{$\overline{\boldsymbol{x}}$} & & \multicolumn{3}{c}{ Biomassa (Mg) } \\
\cline { 2 - 3 } \cline { 6 - 7 } \cline { 6 - 7 } & Ind. & $\mathbf{D A P}(\mathbf{c m})$ & $\mathbf{H T}(\mathbf{m})$ & & $\overline{\boldsymbol{x}}_{(\text {ind.) }}$ & Parcela & Área (ha) \\
\hline 1 & 34 & 18,54 & 17,63 & & 0,13 & 4,53 & 75,51 \\
2 & 50 & 17,40 & 17,09 & & 0,11 & 5,66 & 94,27 \\
3 & 39 & 16,91 & 15,63 & & 0,10 & 4,06 & 67,69 \\
4 & 35 & 17,17 & 15,27 & & 0,11 & 3,72 & 61,95 \\
5 & 42 & 18,11 & 17,31 & & 0,12 & 5,21 & 86,88 \\
6 & 28 & 18,98 & 18,32 & & 0,14 & 3,97 & 66,17 \\
7 & 54 & 17,37 & 16,75 & & 0,11 & 6,03 & 100,57 \\
8 & 45 & 17,93 & 17,13 & & 0,12 & 5,43 & 90,48 \\
9 & 43 & 17,73 & 17,15 & & 0,12 & 5,10 & 84,94 \\
10 & 40 & 17,32 & 15,94 & & 0,11 & 4,44 & 73,99 \\
\hline$\overline{\boldsymbol{x}}$ & 41 & 17,75 & 16,82 & & 0,12 & 4,81 & 80,24 \\
$S$ & 7 & 0,65 & 0,94 & & 0,01 & 0,78 & 13,05 \\
I.C. & 5 & $\pm 0,47$ & $\pm 0,67$ & & $\pm 0,01$ & $\pm 0,56$ & $\pm 9,34$ \\
\hline
\end{tabular}

$\bar{x}$ : média; S: desvio padrão; e I.C.: Intervalo de confiança ao nível de 95\% de probabilidade. Fonte: Autores (2021).

Os valores de biomassa foram transformados de quilograma $(\mathrm{kg})$ para Megagrama $(\mathrm{Mg})$ e extrapolado para hectare (ha). Valores encontrados são similares aos observados por Cordero e Kanninen (2003) estudando biomassa aérea de T. grandis em diferentes idades (5 a 48 anos), os autores encontraram valores de biomassa seca total acima do solo para povoamentos com idades próximas aos 10 anos variando de 200 a $210 \mathrm{Mg} \mathrm{ha}^{-1}$.

\subsection{Biomassa seca acima do solo com variáveis das imagens de Sentinel-2, no período seco e chuvoso}

Observam-se variações significativas e expressivas no comportamento das variáveis independentes do período seco e chuvoso, com diferenças positivas entre 39 a $362 \%$ e negativas de -46 a -72\%, sendo o índice de vegetação NDVI com maior variação entre os períodos (Tabela 8). 
Tabela 8. Estatística descritiva e diferença dos valores das bandas B02, B03, B04, B08 NDVI, EVI-1, EVI-2 e SAVI, em 25/09/2017 (seco) e 03/04/2018 (chuvoso), para as 10 parcelas de um plantio de Tectona grandis em Rolim de Moura, Rondônia.

\begin{tabular}{|c|c|c|c|c|c|c|c|c|}
\hline & \multicolumn{3}{|c|}{ Seco } & \multicolumn{3}{|c|}{ Chuvoso } & \multirow{2}{*}{ p-valor } & \multirow{2}{*}{ Diferença $(\%)$} \\
\hline & $\overline{\bar{x}}$ & $S$ & I.C. & $\bar{x}$ & $S$ & I.C. & & \\
\hline B02 & 0,1812 & 0,0004 & $\pm 0,0003$ & 0,0849 & 0,0006 & $\pm 0,0004$ & $<0,001^{*}$ & $-53 \%$ \\
\hline B03 & 0,1607 & 0,0005 & $\pm 0,0004$ & 0,0866 & 0,0029 & $\pm 0,0021$ & $<0,001 *$ & $-46 \%$ \\
\hline B04 & 0,1703 & 0,0035 & $\pm 0,0025$ & 0,0481 & 0,0012 & $\pm 0,0009$ & $<0,001^{*}$ & $-72 \%$ \\
\hline B08 & 0,2407 & 0,0049 & $\pm 0,0035$ & 0,3336 & 0,0151 & $\pm 0,0108$ & $<0,001 *$ & $39 \%$ \\
\hline NDVI & 0,1711 & 0,0189 & $\pm 0,0135$ & 0,7475 & 0,0133 & $\pm 0,0095$ & $<0,001^{*}$ & $337 \%$ \\
\hline EVI-1 & 0,1951 & 0,0256 & $\pm 0,0183$ & 0,7243 & 0,0312 & $\pm 0,0223$ & $<0,001^{*}$ & $271 \%$ \\
\hline EVI-2 & 0,1067 & 0,0124 & $\pm 0,0089$ & 0,4923 & 0,0224 & $\pm 0,0160$ & $<0,001^{*}$ & $362 \%$ \\
\hline SAVI & 0,2566 & 0,0283 & $\pm 0,0203$ & 1,1210 & 0,0200 & $\pm 0,0143$ & $<0,001^{*}$ & $337 \%$ \\
\hline
\end{tabular}

$\bar{x} \quad$ média; $S$ : desvio padrão; I.C.: Intervalo de confiança ao nível de $95 \%$ de probabilidade; *Significativo $(\mathrm{p}<0,001)$ pelo teste $\mathrm{t}$ pareado. Fonte: Autores (2021).

Nas bandas da região do visível B02, B03, B04 (azul, verde e vermelho), o valor médio de reflectância diminuiu no período chuvoso em relação ao período seco, com variações de -46 a -72\% (Tabela 8). Esse comportamento das bandas do visível é explicado devido à interação da reflectância com os pigmentos fotossintetizantes das folhas, ou seja, quanto maior a densidade de vegetação maior será a absorção da radiação nos pigmentos fotossintetizante, por outro lado quanto menor a densidade vegetal maior será a reflectância, visto que na ausência de folhas, já não ocorre a interação com a vegetação, e sim com o solo exposto (Ponzoni, Shimabukuro \& Kuplich, 2012; Boratto \& Gomide, 2013).

Para a banda 08 (infravermelho próximo), o comportamento da reflectância foi semelhante aos observados para os índices, observa-se que no período seco os valores de reflectância tiveram em média 0,2407, sendo menor que o observado no período chuvoso que foi de 0,3336 , com diferença significativa de 39\%. Este comportamento observado para o infravermelho próximo e os índices de vegetação é explicado de modo inverso ao observado para a região do visível. No período seco tinha menos vegetação, portanto os valores de reflectância foram menores, por outro lado, no período chuvoso a vegetação estava com maior vigor, assim, houve menos absorção pelos pigmentos fotossintetizantes e maior espalhamento nas diferentes camadas das folhas.

Entretanto, para os índices de vegetação os valores médios de reflectância foram menores no período seco, com diferenças expressivas para o EVI-1 de 271\% e EVI-2 de 362\%. O comportamento da variação dos valores dos índices entre os períodos foi semelhante aos do infravermelho próximo, porém com diferenças mais expressivas. Outros autores verificaram comportamento semelhante aos encontrados nesse estudo, confirmando os resultados obtidos (Becerra et al., 2009; Dalla Nora \& Santos, 2010).

\subsubsection{Correlação da biomassa com as variáveis das imagens de Sentinel-2, no período seco e chuvoso}

A matriz de correlação determinou o grau de associação entre as variáveis dependentes e independentes. Os valores de reflectância e dos índices de vegetação no período seco e no chuvoso tiveram correlações fracas a moderadas (Tabelas 9 e 10). No período seco as bandas do visível (B02, B03 e B04) tiveram correlações negativas de ( $r=-0,3307, r=-0,2986$ e r= -0,3823), a banda do infravermelho próximo (B08) e os índices EVI-1, EVI-2, NDVI, SAVI tiveram correlações positivas ( $\mathrm{r}=0,3893$, $\mathrm{r}=$ $0,3961, r=0,4023, r=0,4040, r=0,4040)$ (Tabela 9). 
Tabela 9. Matriz de correlação entre biomassa seca acima do solo (biomassa), reflectância das bandas (B02, B03, B04, B08) e os índices de vegetação (EVI-1, EVI-2, NDVI e SAVI), na data 25/09/2017 (seco), em um plantio de Tectona grandis, Rolim de Moura, Rondônia.

\begin{tabular}{ccccccccc}
\hline & Biomassa & B02 & B03 & B04 & B08 & EVI-1 & EVI-2 & NDVI \\
\hline B02 & $-0,3307$ & & & & & & & \\
B03 & $-0,2986$ & $-0,0129$ & & & & & & \\
B04 & $-0,3823$ & 0,5931 & 0,3616 & & & & & \\
B08 & 0,3893 & $-0,6189$ & $-0,1847$ & $-0,8354$ & & & & \\
EVI-1 & $\mathbf{0 , 3 9 6 1}$ & $-0,6133$ & $-0,2969$ & $-0,9641$ & 0,9507 & & & \\
EVI-2 & $\mathbf{0 , 4 0 2 3}$ & $-0,6330$ & $-0,2757$ & $-0,9488$ & 0,9663 & 0,9983 & & \\
NDVI & $\mathbf{0 , 4 0 4 0}$ & $-0,6321$ & $-0,2853$ & $-0,9575$ & 0,9584 & 0,9994 & 0,9996 & \\
SAVI & $\mathbf{0 , 4 0 4 0}$ & $-0,6321$ & $-0,2853$ & $-0,9575$ & 0,9584 & 0,9994 & 0,9996 & 1,0000 \\
\hline
\end{tabular}

Em destaque as correlações de Pearson das variáveis independentes com a biomassa. Fonte: Autores (2021).

Os valores positivos observados na matriz de correlação são explicados devido às variáveis moverem-se juntas, ou seja, conforme aumento da densidade de folhas, a biomassa tende a aumentar e, em consequência, aumenta-se a reflectância do infravermelho e dos índices de vegetação. Em contrapartida, ocorre o inverso com as bandas B02, B03 e B04, ou seja, quando a densidade vegetal aumenta a reflectância diminui (Ponzoni, Shimabukuro \& Kuplich, 2012).

As correlações das variáveis independentes do período seco com a biomassa foram consideradas fracas $(\mathrm{r}<0,4)$ a desprezível $(\mathrm{r}<0,3)$. Este fato pode ser explicado, pois há uma mudança na quantidade folhas no dossel (IAF - índice de área foliar) e também uma possível alteração na angulação foliar (DAF - distribuição do ângulo foliar), devido á época de aquisição da imagem utilizada (final de setembro), quando o plantio de Tectona grandis está com baixa densidade de folhas, por ser uma espécie caducifólia (Rondon, 2006; Dalla Nora \& Santos, 2010; Pelissari et al., 2014).

É interessante ressaltar, que essa fraca correlação obtida, contradiz a maioria dos trabalhos encontrados na literatura (Watzlawick, Koehler \& Kirchner, 2006; Padrón \& Navarro-Cerrilo, 2007; Matos \& Kirchner, 2008). Porém, estes trabalhos utilizaram imagens de alta resolução espacial, podendo ter causado este efeito.

No período chuvoso, as maiores correlações positivas foram verificadas nas variáveis B08 (0,6413), B03 (0,5960), EVI2 (0,5923) e EVI-1 (0,5546), sendo estas consideradas como moderada correlação. Entretanto, as variáveis B02 e B04 tiveram as menores correlações com a biomassa seca acima do solo (Tabela 10).

Tabela 10. Matriz de correlação entre biomassa seca acima do solo (biomassa), reflectância das bandas (B02, B03, B04, B08) e os índices de vegetação (EVI-1, EVI-2, NDVI e SAVI), na data 03/04/2018, em um plantio de Tectona grandis, Rolim de Moura, Rondônia.

\begin{tabular}{ccccccccc}
\hline & Biomassa & B02 & B03 & B04 & B08 & EVI-1 & EVI-2 & NDVI \\
\hline B02 & 0,0156 & & & & & & & \\
B03 & $\mathbf{- 0 , 5 9 6 0}$ & 0,4229 & & & & & & \\
B04 & $-0,0280$ & 0,7869 & 0,1959 & & & & & \\
B08 & $\mathbf{0 , 6 4 1 3}$ & $-0,0865$ & $-0,1246$ & $-0,4985$ & & & & \\
EVI-1 & $\mathbf{0 , 5 5 4 6}$ & $-0,1905$ & $-0,1108$ & $-0,6275$ & 0,9858 & & & \\
EVI-2 & $\mathbf{0 , 5 9 2 3}$ & $-0,1891$ & $-0,1365$ & $-0,6019$ & 0,9923 & 0,9980 & & \\
NDVI & $\mathbf{0 , 4 5 3 4}$ & $-0,3973$ & $-0,1516$ & $-0,7919$ & 0,9233 & 0,9718 & 0,9638 & \\
SAVI & $\mathbf{0 , 4 5 3 5}$ & $-0,3972$ & $-0,1516$ & $-0,7919$ & 0,9233 & 0,9718 & 0,9638 & 1,0000 \\
\hline
\end{tabular}


Este efeito foi observado em imagens do satélite IKONOS II para estimar biomassa aérea, sendo verificadas correlações negativas para as bandas do visível (Watzlawick, Koehler \& Kirchner, 2006; Ferraz et al., 2013). Para os índices de vegetação, estudos apontam correlações fracas para espécies caducifólias (Becerra, Shimabukuro \& Alvalá, 2009), sendo resultados semelhantes aos encontrados neste estudo.

Entretanto, Watzlawick, Kirchner e Sanquetta (2009) estimando biomassa de um plantio de Pinus taeda L. com imagens do satélite IKONOS II, observaram maiores correlações negativas com biomassa, com as variáveis NDVI $(-0,80)$ e banda MS-4 (infravermelho próximo) (-0,72), contradizendo ao que foi obtido nesse estudo. Este resultado contraditório pode ser explicado devido às características do sensor, período em que as imagens utilizadas foram obtidas e o comportamento espectral da espécie observada.

\subsubsection{Ajuste e seleção de equações de biomassa com as variáveis das imagens de Sentinel-2, no período seco e chuvoso}

As equações para estimar a biomassa seca acima do solo com as variáveis no período seco foram testadas e ajustadas com o modelo Stepwise. Observa-se que nenhum modelo no período seco foi capaz de explicar satisfatoriamente a variação da biomassa seca, isso era esperado já que as variáveis independentes tiveram fraca correlação com a variável dependente (Tabela 11 e Figura 4).

Tabela 11. Equações testadas e ajustadas pelo método Stepwise (Foward e Blackward) para estimar a variável biomassa seca acima do solo com os dados das imagens de Sentinel-2 em 25/09/2017 (BIOMASSA $=b_{0}+b_{1}\left(\right.$ B02) $+b_{2}(B 03)+b_{3}(B 04)+$ $\mathrm{b}_{4}(\mathrm{~B} 08)+\mathrm{b}_{5}\left(\right.$ EVI-1) $+\mathrm{b}_{6}\left(\right.$ EVI-2) $\left.+\mathrm{b}_{7}(\mathrm{NDVI})+\mathrm{b}_{8}(\mathrm{SAVI})\right)$ em um plantio de Tectona grandis em Rolim de Moura, Rondônia.

\begin{tabular}{|c|c|c|c|c|c|c|}
\hline $\mathbf{N}$ & Equação & $\mathbf{F}$ & $\mathbf{R}^{2}$ aj & $\mathrm{S}_{\mathrm{yx}}(\%$ & AIC & BIC \\
\hline 1 & $\begin{array}{l}Y=-8,150885+38,793282(\mathrm{~B} 02)-23,539602(\mathrm{EVI}-1)-40,290208(\mathrm{EVI}-2) \\
+59,195671(\mathrm{NDVI})\end{array}$ & $\underset{\mathrm{s}}{1,32^{\mathrm{n}}}$ & 0,13 & 9,43 & 81,71 & 83,52 \\
\hline 2 & $\begin{array}{l}\mathrm{Y}=-6,984449+35,978452(\mathrm{~B} 02)-3,734553(\mathrm{~B} 03)-22,794274(\mathrm{EVI}-1)- \\
37,351559(\mathrm{EVI}-2)+56,185119(\mathrm{NDVI})\end{array}$ & $\underset{s}{0,92^{\mathrm{n}}}$ & $-0,04$ & 10,31 & 83,26 & 85,37 \\
\hline 3 & $\mathrm{Y}=0,3435312-1,3216589(\mathrm{~B} 04)$ & $\underset{s}{1,37^{\mathrm{n}}}$ & 0,04 & 9,88 & 81,35 & 82,26 \\
\hline 4 & $\mathrm{Y}=-0,109358+0,9466314(\mathrm{~B} 08)$ & $\underset{s}{1,43^{\mathrm{n}}}$ & 0,05 & 9,85 & 81,29 & 82,19 \\
\hline 5 & $\mathrm{Y}=0,08244558+0,18452973(\mathrm{EVI}-1)$ & $\underset{s}{1,49^{\mathrm{n}}}$ & 0,05 & 9,82 & 81,23 & 82,13 \\
\hline 6 & $\mathrm{Y}=0,07713317+0,38740440(\mathrm{EVI}-2)$ & $\underset{\mathrm{s}}{1,55^{\mathrm{n}}}$ & 0,06 & 9,79 & 81,17 & 82,07 \\
\hline 7 & $\mathrm{Y}=0,07471665+0,25559595(\mathrm{NDVI})$ & $\underset{\mathrm{s}}{1,56^{\mathrm{n}}}$ & 0,06 & 9,78 & 81,15 & 82,06 \\
\hline 8 & $\mathrm{Y}=0,07471682+0,17041735(\mathrm{SAVI})$ & $\underset{s}{1,56^{\mathrm{n}}}$ & 0,06 & 9,78 & 81,15 & 82,06 \\
\hline
\end{tabular}

Y: Biomassa seca acima do solo, $\mathrm{Mg} ; \mathrm{R}^{2}$ aj: coeficiente de determinação ajustado; $\mathrm{S}_{\mathrm{yx}}(\%)$ : erro padrão da estimativa; AIC: Critério de Informação de Akaike e BIC: Critério de Informação Bayesiano. ${ }^{n s}$ não significativo ( $\left.p>0,05\right)$; *significativo ( $\left.<<0,05\right)$. Fonte: Autores $(2021)$. 
Figura 4. Distribuição dos resíduos de oito equações de biomassa ajustadas para dez parcelas de um plantio de Tectona grandis com as variáveis da imagem de sentinel-2 no dia 25/09/2017, Rolim de Moura - Rondônia.

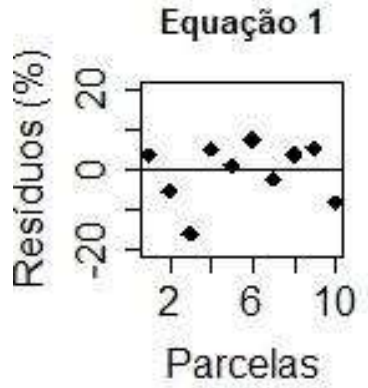

Equação 5

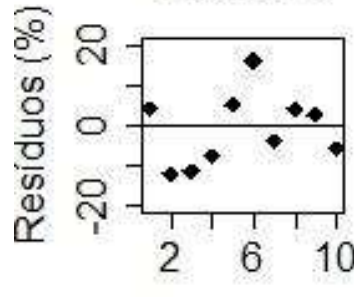

Parcelas

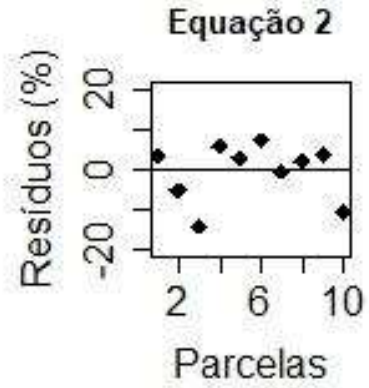

Equação 6

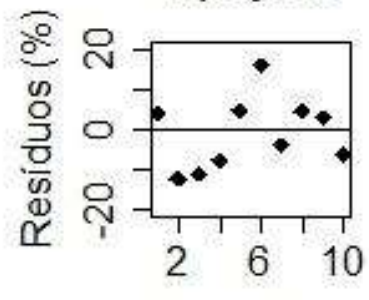

Parcelas

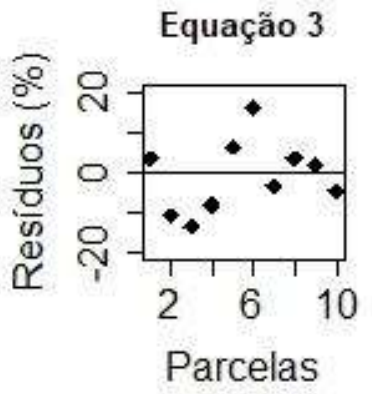

Equação 7

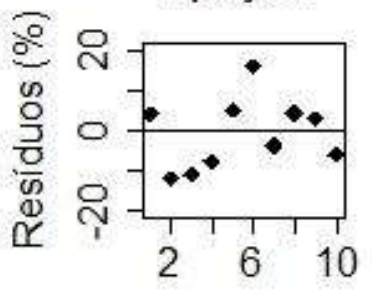

Parcelas
Equação 4

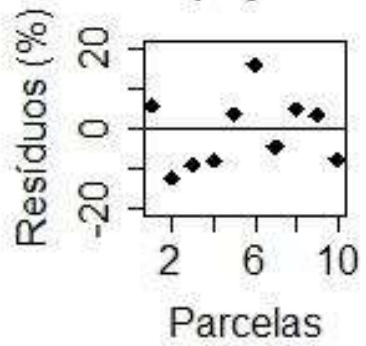

Equação 8

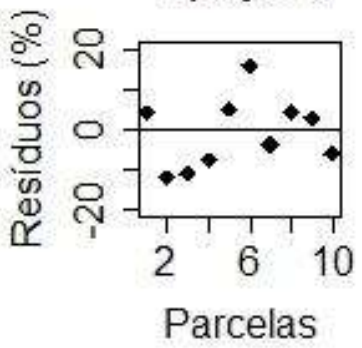

Fonte: Autores (2021).

Observam-se maiores valores de $\mathrm{R}^{2}$ aj e menores valores de Syx\% para as equações 1 e 2 . A equação 1 foi significativa

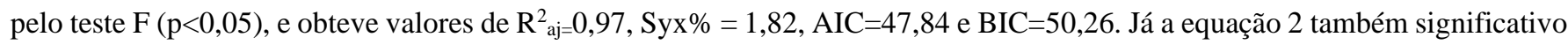
pelo teste $\mathrm{F}(\mathrm{p}<0,05)$, com $\mathrm{R}^{2}{ }_{\mathrm{aj}}=0,96$, Syx \% 2,08, $\mathrm{AIC}=48,31$ e BIC=51,02 (Tabela 12). Levando-se em consideração os menores valores de AIC e BIC, e também a melhor distribuição dos resíduos (Figura 5), foi confirmado que os dois modelos foram superiores.

Tabela 12. Equações testadas e ajustadas pelo método Stepwise (Foward e Blackward) para estimar a variável biomassa seca acima do solo com os dados das imagens de Sentinel-2 em 03/04/2018 (BIOMASSA $=b_{0}+b_{1}\left(B_{02}\right)+b_{2}(B 03)+b_{3}(B 04)+$ $\mathrm{b}_{4}(\mathrm{~B} 08)+\mathrm{b}_{5}\left(\right.$ EVI-1) $+\mathrm{b}_{6}\left(\right.$ EVI-2) $\mathrm{b}_{7}(\mathrm{NDVI})+\mathrm{b}_{8}($ SAVI), em um plantio de Tectona grandis em Rolim de Moura, Rondônia.

\begin{tabular}{|c|c|c|c|c|c|c|}
\hline $\mathbf{N}$ & Equação & $\mathbf{F}$ & $\mathbf{R}^{2}$ aj & $\mathrm{S}_{\mathrm{yx}}(\%)$ & AIC & BIC \\
\hline 1 & $\begin{array}{l}\mathrm{Y}=35,625331-528,123868(\mathrm{~B} 02)-2,653078(\mathrm{~B} 03)+273,491(\mathrm{~B} 04)+ \\
92,572857(\mathrm{EVI}-1)-108,785571(\mathrm{EVI}-2)-22,807912(\mathrm{NDVI})\end{array}$ & $44,92 *$ & 0,97 & 1,83 & 47,84 & 50,26 \\
\hline 2 & $\begin{array}{l}\mathrm{Y}=32,328401-436,242089(\mathrm{~B} 02)-2,705406(\mathrm{~B} 03)+242,508367(\mathrm{~B} 04)- \\
23,898852(\mathrm{~B} 08)+76,191412(\mathrm{EVI}-1)- \\
27,034569(\mathrm{NDVI})\end{array}$ & $29,99 *$ & 0,96 & 2,08 & 48,31 & 51,02 \\
\hline 3 & $\mathrm{Y}=0.1314721-0.2709730(\mathrm{~B} 04)$ & $0,01^{\mathrm{ns}}$ & $\begin{array}{l}- \\
0,12\end{array}$ & 10,69 & 82,92 & 83,84 \\
\hline 4 & $Y=-0.05118214+0.50850627(\mathrm{~B} 08)$ & $5,59^{*}$ & 0,34 & 8,21 & 77,63 & 78,54 \\
\hline 5 & $Y=-0.03552204+0.21259142(E V I-1)$ & $3,55^{\mathrm{ns}}$ & 0,22 & 8,91 & 79,26 & 80,16 \\
\hline 6 & $\mathrm{Y}=-0.0373193+0.3163820(\mathrm{EVI}-2)$ & $4,32^{\mathrm{ns}}$ & 0,27 & 8,62 & 78,61 & 79,52 \\
\hline 7 & $\mathrm{Y}=-0.1855012+0.4066514(\mathrm{NDVI})$ & $2,07^{\mathrm{ns}}$ & 0,11 & 9,53 & 80,63 & 81,54 \\
\hline 8 & $Y=-0.1854740+0.2711122($ SAVI $)$ & $2,07^{\mathrm{ns}}$ & 0,11 & 9,53 & 80,63 & 81,54 \\
\hline
\end{tabular}

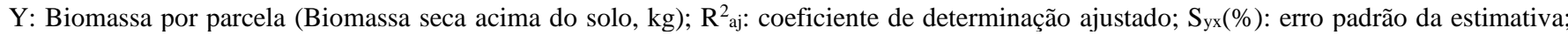
AIC: Critério de Informação de Akaike e BIC: Critério de Informação Bayesiano. ${ }^{N S}$ não significativo ( $\left.p>0,05\right)$; *significativo (p < 0,05). Fonte: Autores (2021). 
Figura 5. Distribuição dos resíduos de oito equações de biomassa ajustadas para dez parcelas de um plantio de Tectona grandis, com as variáveis das imagens do satélite Sentinel-2 no dia 03/04/2018, Rolim de Moura - RO.

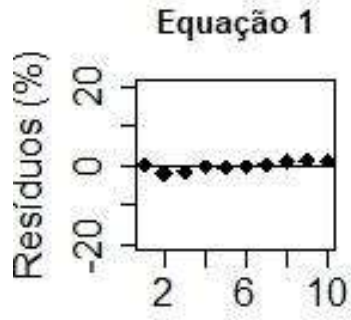

Parcelas

Equação 5

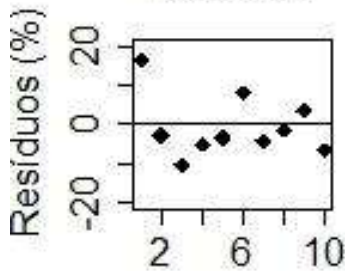

Parcelas
Equação 2

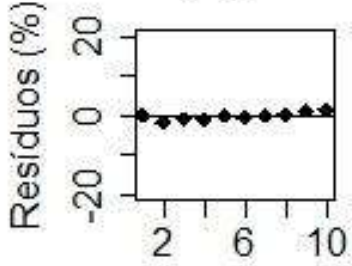

Parcelas

Equação 6

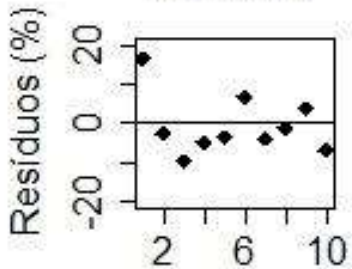

Parcelas
Equação 3

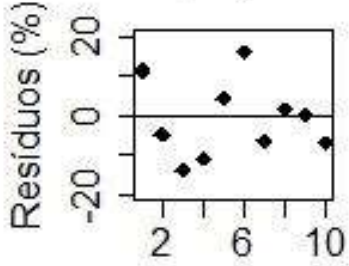

Parcelas

Equação 7

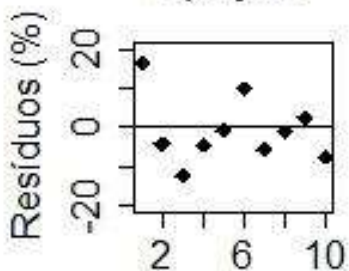

Parcelas
Equação 4

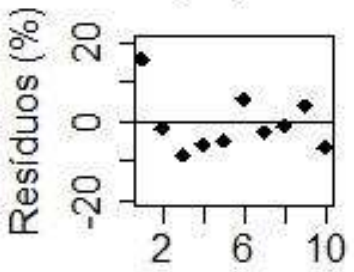

Parcelas

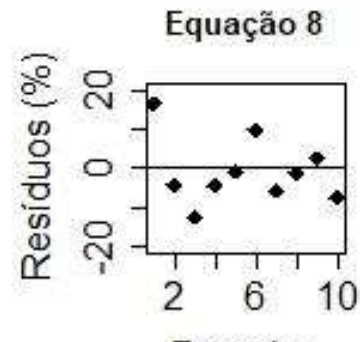

Fonte: Autores (2021).

A Equação 1 foi considerada como a mais adequada para estimar biomassa seca acima do solo, visto que, a mesma foi levemente superior à Equação 2. Estes resultados alcançados pelos ajustes das equações foram considerados satisfatórios, pois são semelhantes ao estudo de Walzlawick, Koehler e Kirchner, (2006), no qual ajustaram equações para estimativas de biomassa com uso do método Stepwise e utilizando imagens do satélite IKONOS para espécie de Pinus taeda L, encontrando valores de $\mathrm{R}^{2}$ aj de 0,84 Syx\% de 20,39 para biomassa arbórea. Em outro estudo, Upgupta, Singh e Tiwari, (2015) utilizando imagens de alta resolução (LISS-IV e Quick-Bird) para plantios florestais de Tectona grandis L.f, obtiveram valores de Rªj= 0,65 e Syx\%= 9,89, valores esses inferiores aos encontrados neste estudo, confirmando que as equações se ajustaram bem para as estimativas de biomassa seca acima do solo.

\subsubsection{Quantificação e espacialização da biomassa seca acima do solo em um plantio de Tectona grandis}

No presente estudo um dos objetivos é a espacialização e quantificação da biomassa acima do solo na área de estudo. Assim, utilizando a equação 1 do período chuvoso (04/03/2018) foi gerada uma tabela com a biomassa estimada (Tabela 13) e um mapa, sendo cada pixel a quantidade estimada de biomassa acima do solo (Figura 6). 
Tabela 13. Biomassa real estimada com os indivíduos e biomassa estimada com os dados das imagens do Sentinel-2, por parcela.

\begin{tabular}{|c|c|c|c|}
\hline Parcelas & $\begin{array}{c}\text { Biomassa estimada com os } \\
\text { indíviduos }{ }^{1}\left(\mathrm{Mg} \mathrm{ha}^{-1}\right)\end{array}$ & $\begin{array}{c}\text { Biomassa estimada com as } \\
\text { imagens }^{2}\left(\mathrm{Mg} \mathrm{ha}^{-1}\right)\end{array}$ & Resíduos (Mg) \\
\hline 1 & 75,51 & 76,78 & $-1,27$ \\
\hline 2 & 94,27 & 88,74 & 5,53 \\
\hline 3 & 67,69 & 70,28 & $-2,58$ \\
\hline 4 & 61,95 & 70,94 & $-9,00$ \\
\hline 5 & 86,88 & 83,05 & 3,82 \\
\hline 6 & 66,17 & 74,15 & $-7,99$ \\
\hline 7 & 100,57 & 94,65 & 5,92 \\
\hline 8 & 90,48 & 79,39 & 11,09 \\
\hline 9 & 84,94 & 77,82 & 7,12 \\
\hline 10 & 73,99 & 72,97 & 1,02 \\
\hline$\overline{\boldsymbol{x}}$ & 80,24 & 78,88 & 1,37 \\
\hline$S$ & 13,05 & 7,91 & 6,58 \\
\hline I.C. & $\pm 9,33$ & 5,66 & 4,70 \\
\hline
\end{tabular}

$\bar{x}$ : média; S: desvio padrão; I.C.: Intervalo de confiança ao nível de $95 \%$ de probabilidade; ${ }^{1}$ Biomassa estimada com os indivíduos: média da biomassa da parcela estimada com os dados de inventário, utilizando a equação: InY $=-2,6743205+2,2341052 \ln D A P+0,3548152 \ln H T$; ${ }^{2}$ Biomassa estimada com os dados da imagem do satélite Sentinel-2, utilizando a equação: $\mathrm{Y}=35,625331-528,123868(\mathrm{~B} 02)-2,653078$ $(\mathrm{B} 03)+273,491(\mathrm{~B} 04)+92,572857(\mathrm{EVI}-1)-108,785571(\mathrm{EVI}-2)-22,807912(\mathrm{NDVI})$. Fonte: Autores (2021).

Figura 6. Mapeamento de biomassa acima do solo no plantio de Tectona grandis, Rolim de Moura, Rondônia.

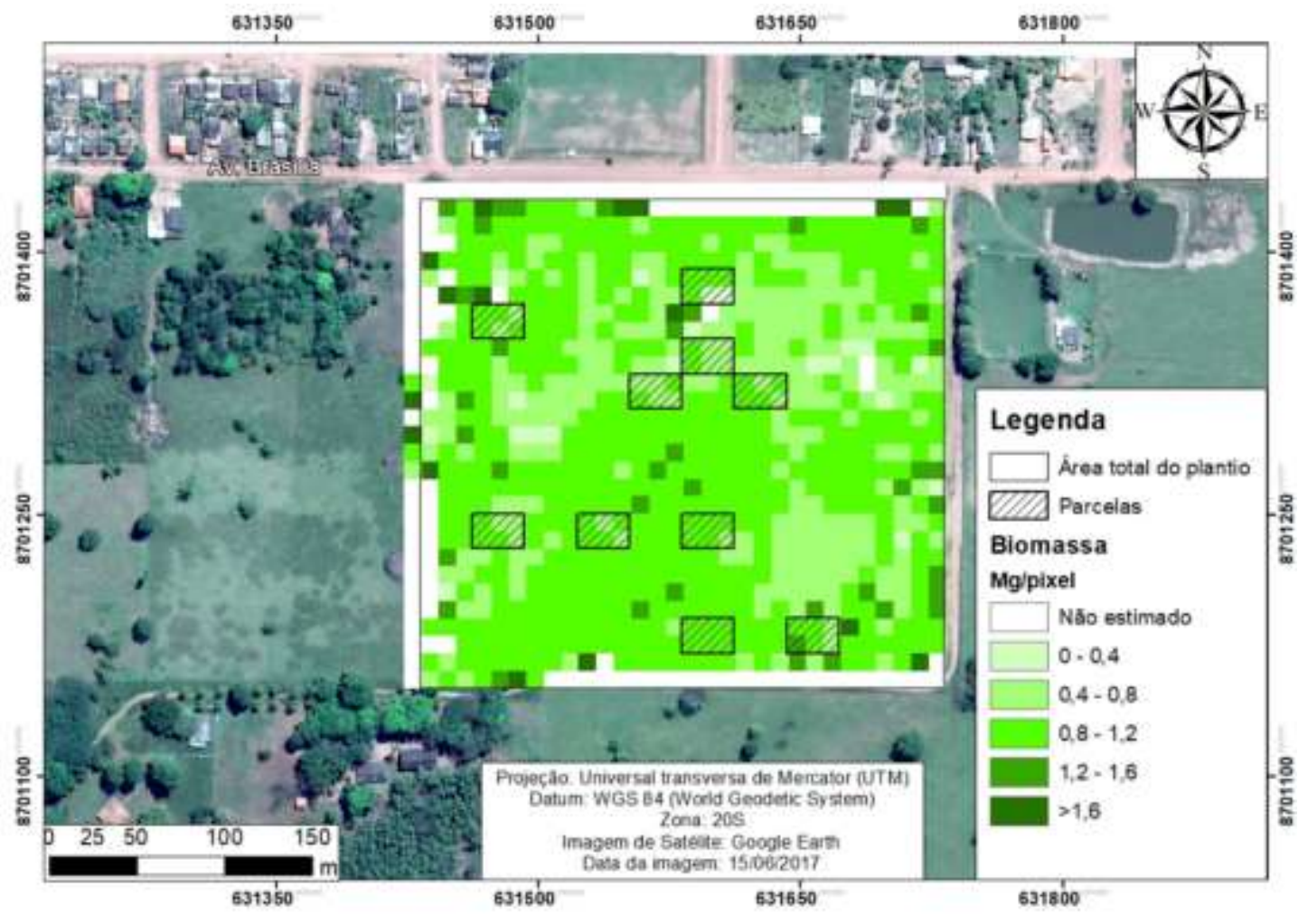

Fonte: Autores (2021).

Utilizando-se de modelos, regressões múltiplas com informações de imagens de satélite, verifica-se que os resíduos das estimativas foram pequenos, sendo a maior superestimativa verificada na parcela 8 com variação de 11,09\%, e a maior subestimativa na parcela 4 com $9 \%$, ademais, a menor variação foi encontrada na parcela 10. Portanto, o uso de imagens do satélite Sentinel-2 pode ser utilizado para estimar biomassa em plantios de Tectona grandis, pois os resultados obtidos neste trabalho foram satisfatórios. 


\section{Conclusão}

O modelo de Schumacher e Hall (1993) foi eficiente para realizar estimativas de biomassa seca acima do solo para os 20 indivíduos, com os dados das variáveis obtidas a campo. Os resultados foram propícios para realizar estimativas da variável biomassa em função dos dados das imagens do satélite Sentinel-2.

As melhores correlações com biomassa seca acima do solo foram verificadas com as variáveis provenientes das imagens de Sentinel-2 no período chuvoso, sendo que as melhores correlações foram verificadas com as bandas B08, B03, e os índices EVI-1 e EVI-2.

As estimativas de biomassa para o período seco não foram efetivas nos ajustes dos modelos para estimativas de biomassa, talvez em virtude de a imagem ter sido obtida em uma época em que a espécie se encontrava desprovida de folhas, a qual apresenta características caducifólia. Entretanto, os resultados para o período chuvoso foram satisfatórios, o que reforça ainda mais a utilização de técnicas de sensoriamento remoto para o período com maior densidade de vegetação.

As estimativas das variáveis utilizando dados das imagens do satélite Sentinel-2 propiciam realizar a quantificação de biomassa seca acima do solo. É bom salientar, que os resultados obtidos nesse estudo, são válidos para o plantio de Tectona grandis L. f, nas condições encontradas para o plantio (idade, espécie, espaçamento, desbastes e localização), pois os resultados podem variar para os diferentes tipos de plantio, além dos diferentes métodos de determinar a biomassa seca acima do solo.

\section{Referências}

Alba, E., Mello, E. P., Marchesan, J., Silva, E. A., Tramontina, J., \& Pereira, R. S. (2017). Spectral characterization of forest plantations with Landsat 8/OLI images for forest planning and management. Pesquisa Agropecuária Brasileira, 52 (11), 1072-1079. http://dx.doi.org/10.1590/S0100-204X2017001100013

Alemdag, I. S., \& Stiell, W. M. (1982). Spacing and age effects on biomass production in red pine plantations. The Forestry Chronicle, 58 (5), $220-224$. https://doi.org/10.5558/tfc58220-5

Alvares, C. A., Stape, J. L., Sentelhas, P. C., De Moraes, G., Leonardo, J., \& Sparovek, G. (2013). Köppen's climate classification map for Brazil. Meteorologische Zeitschrift, 22 (6), 711-728. http://dx.doi.org/10.1127/0941-2948/2013/0507

Becerra, J. A. B., Shimabukuro, Y. E., \& Alvala, R. (2009). Relação do padrão sazonal da vegetação com a precipitação na região do cerrado usando índices espectrais de vegetação. Revista Brasileira de Meteorologia, 24 (2), 125-134. https://doi.org/10.1590/S0102-77862009000200002

Bohrer, P., Chaubey, O. P., \& Singhal, P K. (2013). Biomass Accumulation and Carbon Sequestration in Tectona grandis Linn. f. and Gmelina arborea Roxb. International Journal of Bio-science and Bio-technology, 5 (3), 153-174. https://www.earticle.net/Article/A207142

Boratto, I. M., \& Gomide, R. L. (2013). Aplicação dos índices de vegetação NDVI, SAVI e IAF na caracterização da cobertura vegetativa da região Norte de Minas Gerais. In: Embrapa Milho e Sorgo-Artigo em anais de congresso (ALICE). In: Simpósio brasileiro de sensoriamento remoto, 16, 2013, Foz do Iguaçu. Anais... São José dos Campos: INPE, 7345-7352.

Caldeira, M. V. W., Watzlawick, L. F., Viera, M., Balbinot, R., \& Castro, K. C. (2015). Biomassa e carbono orgânico em povoamentos de Araucaria angustifolia (Bertol.) Kuntze. Ciência Florestal, 25 (4), 1027-1034. https://doi.org/10.5902/1980509820664

Cerqueira, C. L., Lisboa, G. S., França, L. C. J., Môra, R., Marques, G. M., Salles, T. T., \& Brianezi, D. (2017). Modelagem da altura e volume de Tectona grandis LF na mesorregião Nordeste do Pará. Nativa, 5, 606-611. http://www.ufmt.br/nativa

Coelho, I. D. A. M., Serpa, P. R. K., Silva, J. P. F., Nogueira, M., Coelho, O. D. A. M., \& Junior, J. M. C. (2013). Caracterização da produção florestal em áreas de assentamentos rurais localizados no sertão pernambucano. Revista CIENTEC, 5 (1), 78-84.

Cordero, L. P., \& Kanninen, M. (2003). Aboveground biomass of Tectona grandis plantations in Costa Rica. Journal of Tropical Forest Science, 199-213. https://www.jstor.org/stable/23616336

Cramer, W., Bondeau, A., Woodward, F. I., Prentice, I. C., Betts, R. A., Brovkin, V., \& Kucharik, C. (2001). Global response of terrestrial ecosystem structure and function to $\mathrm{CO} 2$ and climate change: results from six dynamic global vegetation models. Global change biology, 7 (4), 357-373. https://doi.org/10.1046/j.1365-2486.2001.00383.x

ASF (2017). ALOS PALSAR Radiometric Terrain Corrected high res. Includes Material c JAXA/METI.

Dalla Nora, E. L., \& Santos, J. E. D. (2010). Análise da dinâmica sazonal de duas formações florestais do bioma mata atlântica com base em índices de vegetação. Revista Perspectiva, 34 (125), 41-51. https://www.uricer.edu.br/site/pdfs/perspectiva/125_73.pdf

Davidson, O., De Coninck, H., Loos, M., \& Meyer, L. (2005). IPCC special report on carbon dioxide capture and storage. Prepared by Working Group III of the Intergovernmental Panel on Climate Change. Cambridge, United Kingdom and New York, NY, USA, 442. 
Dick, G., Schumacher, M. V., Momolli, D. R., Santos, J. C., Ludvichak, A. A., Guimarães, C. C. \& Souza, H. P. (2016). Quantificação da biomassa e nutrientes em um povoamento de Eucalyptus dunnii Maiden estabelecido no Bioma Pampa. Revista Ecologia e Nutrição Florestal-ENFLO, 4(1), 1-9. http://dx.doi.org/10.5902/2316980X20589

Drusch, M, Del Bello, U, Carlier, S, Colin, O, Fernandez, V, Gascon, F \& Meygret, A (2012). Sentinel-2: ESA's optical high-resolution mission for GMES operational services. Remote sensing of Environment, 120, 25-36. https://doi.org/10.1016/j.rse.2011.11.026

Embrapa (1979). Empresa Brasileira De Pesquisa Agropecuária - Embrapa. Serviço Nacional de Levantamento e Conservação de Solos (Rio de Janeiro, RJ). Súmula da 10. Reunião Técnica de Levantamento de Solos. (EMBRAPA-SNLCS. Micelânea, 1). 83p.

ESA (2018): HTTPS://earth.esa.int/web/sentinel/userguides/sentinel2msi/resolutions/spatial. Recuperado de março de 2018.

Ferreira, L. G., \& Huete, A. R. (2004). Assessing the seasonal dynamics of the Brazilian Cerrado vegetation through the use of spectral vegetation indices. International Journal of Remote Sensing, 25 (10), 1837-1860. https://doi.org/10.1080/0143116031000101530

Ferraz, A. S., Soares, V. P., Soares, C. P. B., Ribeiro, C., \& Gleriani, J. M. (2013). Uso de imagens do satélite IKONOS II para estimar biomassa aérea de um fragmento de floresta estacional semidecidual. Simpósio brasileiro de sensoriamento remoto, 16, 2794-2801.

Finger, CAG (2006). Biometria Florestal. UFSM. 2006.

Gurgel, H. C., \& Ferreira, N. J. (2003). Annual and interannual variability of NDVI in Brazil and its connections with climate. International Journal of Remote Sensing, 24 (18), 3595-3609. https://doi.org/10.1080/0143116021000053788

Huete, A. R., Liu, H., \& Van Leeuwen, W. J. (1997). The use of vegetation indices in forested regions: issues of linearity and saturation. In: Geoscience and Remote Sensing, 1997. IGARSS'97. Remote Sensing-A Scientific Vision for Sustainable Development. 1997 IEEE International. IEEE, 1966-1968. https://doi.org/10.1109/IGARSS.1997.609169

Huete, A., Didan, K., Miura, T., Rodriguez, E. P., Gao, X., \& Ferreira, L. G. (2002). Overview of the radiometric and biophysical performance of the MODIS vegetation indices. Remote sensing of environment, 83 (1-2), 195-213. https://doi.org/10.1016/S0034-4257(02)00096-2

Huete, A. R. (1988). A Soil-Adjusted Vegetation Index (SAVI). Remote Sensing of Environment, New York, 25 (3), 295-309. https://doi.org/10.1016/00344257(88)90106-X

Husch, B, Beers, T. W., \& Kershaw Jr. J. A. (2003). Forest Mesnuration. (4th ed.), Hoboken, John Wiley \& Sons, INC. 443p.

IBÁ - Indústria Brasileira De Árvores (2018). Relatório anual da IBÁ 2017, ano base 2016. 80p. http://www.iba.org

IBGE (2012). Banco de dados georreferenciado dos recursos naturais da Amazônia legal. ftp://geoftp.ibge.gov.br/cartas_e_mapas/

Jensen, J. R. (2009). Sensoriamento remoto do ambiente: uma perspectiva em recursos naturais. Parêntese.

Jiang, Z., Huete, A. R., Didan, K., \& Miura, T. (2008). Development of a two-band enhanced vegetation index without a blue band. Remote sensing of Environment, 112 (10), 3833-3845. https://doi.org/10.1016/j.rse.2008.06.006

Junges, A. H., Alves, G., \& Fontana, D. C. (2007). Estudo indicativo do comportamento do NDVI e EVI em lavouras de cereais de inverno da região norte do Estado do Rio Grande do Sul, através de imagens MODIS. Anais XIII Simpósio Brasileiro de Sensoriamento Remoto, Florianópolis, Brasil, 241-248.

Justice, C O., Vermote, E., Townshend, J. R., Defries, R., Roy, D. P., Hall, D. K., \& Lucht, W. (1998). The Moderate Resolution Imaging Spectroradiometer (MODIS): Land remote sensing for global change research. IEEE transactions on geoscience and remote sensing, 36 (4), 1228-1249. https://doi.org/10.1109/36.701075

Lima, I. L. D., Florsheim, S. M. B., \& Longui, E. L. (2009). Influência do espaçamento em algumas propriedades físicas da madeira de Tectona grandis L.f Linn. Revista Cerne, 15 (2), 244-250. http://www.redalyc.org/articulo.oa?id=74413018013

Lucena, A. P. D. (2014). O uso do IVDN no estudo da degradação ambiental de bacias hidrográficas do litoral sul do estado da Paraíba. 105 f. Dissertação (Mestrado em Engenharia Urbana) - Universidade Federal da Paraí-ba, João Pessoa, 2014. https://repositorio.ufpb.br/jspui/handle/tede/5535

Macedo, R. L. G., Gomes, J. E., Venturin, N., \& Salgado, B. G. (2005). Desenvolvimento inicial de Tectona grandis Lf (teca) em diferentes espaçamentos no município de Paracatu, MG. Cerne, 11 (1). http://www.redalyc.org/articulo.oa?id=74411107

Machado, L. A. T., Laurent, H., Dessay, N., \& Miranda, I. (2004). Seasonal and diurnal variability of convection over the Amazonia: a comparison of different vegetation types and large scale forcing. Theoretical and Applied Climatology, 78 (1-3), 61-77. https://doi.org/10.1007/s00704-004-0044-9

Malhi, Y., Aragão, L. E., Galbraith, D., Huntingford, C., Fisher, R., Zelazowski, P., \& Meir, P. (2009). Exploring the likelihood and mechanism of a climatechange-induced dieback of the Amazon rainforest. Proceedings of the National Academy of Sciences, 106 (49), $20610-20615$. https://doi.org/10.1073/pnas.0804619106

Martinelli, L. A., Moreira, M. Z., Brown, I. F., \& Victoria, R. L. (1994). Incertezas associadas às estimativas de biomassa em florestas tropicais: o exemplo de uma floresta situada no estado de Rondônia. Anais do Seminário de Emissão x Sequestro de CO2: uma nova oportunidade de negócios para o Brasil, 221.

Matos, F. D. A., \& Kirchner, F. F. (2008). Estimativa de Biomassa da Floresta Ombrófila densa de terra firme na Amazônia central com o satélite Ikonos II. Floresta, 38 (1), 157-171. http://dx.doi.org/10.5380/rf.v38i1.11036

Midgley, S., Somaiya, R. T., Stevens, P. R., Brown, A., Nguyen, D. K, \& Laity, R. (2015). Planted teak: global production and markets, with reference to Solomon Islands. Australian Centre for International Agricultural Research. 85, 92. http://aciar.gov.au/files/tr85-web.pdf 
Miranda, D. L. C., Melo, A. C. G., \& Sanquetta, C. R. (2011). Equações alométricas para estimativa de biomassa e carbono em árvores de reflorestamentos de restauração. Revista Árvore, 35 (3), 679-689. https://doi.org/10.1590/S0100-67622011000400012

Mukaka, M. M. (2012). A guide to appropriate use of correlation coefficient in medical research. Malawi Medical Journal, 24 (3), 69-71. http://www.mmj.medcol.mw/

Neter, J., Kutner M. H., Nachtsheim, C. J., \& Wasserman, W. (1996). Applied Linear Statistical Models, Boston, MA,McGraw-Hill.

Nicoletti, M. F., Silva, E., \& Floriani, M. M. P. (2015). Metodologia não destrutiva para quantificação do volume e biomassa do fuste em remanescente florestal. Nativa, 3 (4), 287-291. https://doi.org/10.31413/nativa.v3i4.3062

Padrón, E., \& Navarro-cerrillo, R M. (2007). Biomasa aérea en ecosistemas de Prosopis pallida (Humb. and Bonpl. ex Willd.) HBK usando imágenes Landsat 7 ETM+. Revista chilena de historia natural, 80 (1), 43-53. http://dx.doi.org/10.4067/S0716-078X2007000100004

Pelissari, A. L., Guimarães, P. P., Behling, A., \& Ebling, A. (2014). Cultivo da teca: características da espécie para implantação e condução de povoamentos florestais. Agrarian Academy, 1 (1), 127-145. http://www.conhecer.org.br/Agrarian\%20Academy/2014a/cultivo.pdf

Ponzoni, F. J., Shimbukuro, Y. E., \& Kuplich, T. M. (2007). Sensoriamento remoto no estudo da vegetação. São José dos Campos: Parêntese.

R Core Team (2018). R: A language and environment for statistical computing. R Foundation for Statistical Computing, Vienna, Austria. https://www.Rproject.org/

Rondon, E. V. (2006). Estudo de biomassa de Tectona grandis Lf sob diferentes espaçamentos no estado de Mato Grosso. Revista Árvore, 30(3), 337-341. https://doi.org/10.1590/S0100-67622006000300003

Rouse Jr, J W, Haas, R H, Schell, J. A \& Deering, D. W. (1973). Monitoring the vernal advancement and retrogradation (green wave effect) of natural vegetation. NASA/GSFC Type III Final Report, Greenbelt, Md, 371. https://ntrs.nasa.gov/api/citations/19730009607/downloads/19730009607.pdf

Sanquetta, C. R \& Balbinot, R (2002). Métodos de determinação de biomassa florestal. As florestas e o carbono. Curitiba, p. 119-140.

Sanquetta, C. R., Behling, A, Corte, A. P D, Simon, A, Pscheidt, H, Ruza, M. S., \& Mochiutti, S (2014). Estoques de biomassa e carbono em povoamentos de acácia negra em diferentes cidades no Rio Grande do Sul. Scientia Forestalis, Piracicaba, 42 (103), 361-370. http://www.alice.cnptia.embrapa.br/alice/handle/doc/996504

Sanquetta, M. N. I, Sanquetta, C. R, Mognon, F, Dalla Corte, A. P, Rodrigues, A. L., \& Maas, G. C B. (2015). Ajuste de equações hipsométricas para a estimação da altura total de indivíduos jovens de teca. Científica, 43 (4), 400-406. http://dx.doi.org/10.15361/1984-5529.2015v43n4p400-406

Schoeninger, E R, Koehler, H. S, Botelho, M. F, Watzlawick, L. F., \& De Oliveira, P. C (2009). Uso de redes neurais artificiais para mapeamento de biomassa e carbono orgânico no componente arbóreo de uma floresta ombrófila. Ambiência, 4 (2), 179-195. Recuperação em https://revistas.unicentro.br/index.php/ambiencia/article/view/138

Scolforo, J. R, Mello, J. D, Oliveira, A. D, Pereira, R. M, Souza, F. N, \& Guedes, I. D. L. (2008). Volumetria, peso de matéria seca e carbono. Inventário florestal de Minas Gerais: Cerrado: florística, estrutura, diversidade, similaridade, distribuição diamétrica e de altura, Volumetria, tendências de crescimento e áreas aptas para manejo florestal. Lavras: Ed da UFLA, 361-438.

Sedam (Secretaria de Desenvolvimento Ambiental do Estado de Rondônia) (2010). Boletim Climático do Estado de Rondônia. 4, Porto Velho (RO).

Tropical Rainfall Measuring Mission (TRMM) (2011). TRMM (TMPA) Rainfall Estimate L3 3 hour 0.25 degree x 0.25 degree V7, Greenbelt, MD, Goddard Earth Sciences Data and Information Services Center (GES DISC). https://doi.org/10.5067/TRMM/TMPA/3H/7

Upgupta, S, Singh, S \& Tiwari, P. S (2015). Estimation of aboveground phytomass of plantations using digital photogrammetry and high resolution remote sensing data. Journal of the Indian Society of Remote Sensing, 43 (2), 311-323. https://doi.org/10.1007/s12524-014-0401-9

Vendruscolo, J (2012). Atributos físicos e químicos de diferentes tipos de solos sob quatro coberturas vegetais na área ciliar do Igarapé D’Alincourt-RO. Dissertação de Mestrado, Areia: Universidade Federal da Paraíba, 58p.

Viera, M., Schumacher, M. V., Trüby, P., \& De Araújo, E. F. (2013). Biomassa e nutrientes em um povoamento de Eucalyptus urophylla x Eucalyptus globulus, em Eldorado do Sul-RS. Revista Ecologia e Nutrição Florestal-ENFLO, 1 (1), 1-13. http://dx.doi.org/10.13086/2316-980x.v01n01a01

Watzlawick, L F., Kirchner, F. F., \& Sanquetta, C. R. (2009). Estimativa de biomassa e carbono em floresta com araucária utilizando imagens do satélite IKONOS II. Ciência Florestal, 19 (2). https://doi.org/10.1007/s12524-014-0401-9

Watzlawick, L. F., Koehler, H. S., \& Kirchner, F F (2006). Estimativa de biomassa e carbono em plantios de Pinus taeda L. utilizando imagens do satélite IKONOS II. Ciência e Natura, 28 (1), 45. https://doi.org/10.5902/2179460X9708 